\title{
Evolving interest and sense of self in an environmental citizen science program
}

\author{
Yurong He $^{1}$, Julia K. Parrish ${ }^{1}$, Shawn Rowe ${ }^{2}$ and Timothy Jones $^{1}$
}

\begin{abstract}
Citizen science is a growing phenomenon across many branches of environmental science facilitating both increased science literacy and the collection of highly rigorous, longitudinal data. Understanding the motivations of adults to join and remain active in citizen science programs is important as the diversity and abundance of opportunities for public participation in science grow. We conducted a mixed-methods study of newly recruited and "seasoned" (1 year plus) participants in the Coastal Observation and Seabird Survey Team, a hands-on, environmental citizen science program focused on adult coastal residents, to explore the degree to which engagement, measured as time in the program, influenced motivation. We used constructs of functionalism, person-object theory of interest, and activity theoretic approaches to situational identity to deconstruct motivation into three interacting components: objects of interest, actions directed toward those objects, and situated senses of self. Newly recruited participants came with a strong interest in being outside on the beach and learning about birds and saw themselves as data collectors defined in part by their birding and degree/ job-based credentials and their social relationships. By contrast, seasoned participants aligned their interests and situational identity more directly with the program, calling out the importance of program data and results, elevating science-based actions such as monitoring over learning, intensifying their desire to contribute to science, subjugating individual attributes in favor of their science identity, and increasing their sense of self-worth attached to the project. Our results suggest that hands-on, environmental citizen science programs focused on adults should shape their data collector roles and projects around context-specific motivations including senses of place and biodiversity, support both the altruistic and self-interest needs of participants, and combine rigorous science experience with social interaction.
\end{abstract}

Key Words: beached birds; citizen science; COASST; cultural-historical activity theory; functionalism; interest; motivation; person-object engagement

\section{INTRODUCTION}

Within the last several decades there has been tremendous growth in citizen science (Cooper et al. 2007) as indicated by both the increase in peer-reviewed publications (Stepenuck and Green 2015, McKinley et al. 2017) and exponential growth in programs and participant numbers (Theobald et al. 2015, Parrish et al. 2019). This is not a new phenomenon; public participation in science traces its lineage in the West to the traditions of the naturalist, the almanac keeper, and the amateur collector (MillerRushing et al. 2012). Growth from these historic roots is evident in the current diversity of approaches to nonprofessional involvement in environmental science, defined herein as out of doors, nature focused, and grounded in issues or questions, from ecotourism (Caissie and Halpenny 2003) and hobbyist activities (Jones et al. 2017, 2018) to agency- and academic-sponsored environmental monitoring (Dickinson et al. 2010) to place-based, community-sponsored social justice programs (Ballard et al. 2008). Although some public participation programs focus on youths (National Research Council 2009, Ballard et al. 2017), many programs actively recruit adults (Burgess et al. 2017, National Academies of Sciences, Engineering, and Medicine 2018). Unlike students within the formal education system, these "free-choice" learners (Falk et al. 2007) may join, continue, or withdraw from any given program at any time.

Understanding the motivations that adults have to participate in free-choice activities is essential for successful and sustainable program design within citizen science (Nov et al. 2014, Wright et al., 2015, West and Pateman 2016) and can also shed light on questions of motivation and engagement more broadly. Katz (1960) suggested that participation in many different types of activities is broadly dependent on whether a given activity serves a positive function for the individual, satisfying specific motivational needs. Clary and Snyder (1999) used this approach to create the Volunteer Functions Inventory, a general survey instrument assessing six basic categories fundamental to volunteering (Table 1). Subsequent work on environmentoriented volunteer motivations (e.g., Bruyere and Rappe 2007, Asah and Blahna 2013, Carballo-Cárdenas and Tobi 2016, Domroese and Johnson 2017) has adapted these basic categories (Table 1), while simultaneously uncovering domain-specific motivators for participation including science broadly, as well as nature or the environment (Ryan et al. 2001, Frensley et al. 2017, Ganzevoort et al. 2017, Jones et al. 2017). Finally, studies of environmental volunteerism have highlighted situation-specific motivators, or motivations attached to the specifics of the activity at hand (Table 1). These include getting outside, as well as aspects of each specific program (Bruyere and Rappe 2007, Wright et al. 2015). In sum, this work collectively suggests basic motivations broadly applicable across many types of volunteerism; domainspecific motivations attached to broad disciplines (e.g., discovery science vs. medicine) and/or categories of activity (e.g., scientific research vs. social services) relevant to the work; and situational motivations describing specific aspects of program or place. We refer to these categorical levels as structured functionalism.

\footnotetext{
${ }^{1}$ School of Aquatic and Fishery Sciences, University of Washington, ${ }^{2}$ College of Education and Oregon Sea Grant, Oregon State University
} 
Table 1. Structural functionalism as defined by the basic functions of volunteering outlined by Katz (1960) and adapted by Clary and Snyder (1999) in their Volunteer Functions Inventory (VFI) and ensuing environmental volunteerism studies (see text). The latter studies also define the domain-specific and situationspecific functions we have outlined.

\begin{tabular}{|c|c|c|}
\hline $\begin{array}{l}\text { Functional } \\
\text { Category }\end{array}$ & $\begin{array}{l}\text { Functions Fulfilled by } \\
\text { Volunteering (VFI) }\end{array}$ & $\begin{array}{l}\text { Specific to Environmental } \\
\text { Volunteerism }\end{array}$ \\
\hline \multirow{6}{*}{ Basic } & Values & $\begin{array}{l}\text { Project goals align with personal } \\
\text { values and beliefs, often } \\
\text { connected to the environment }\end{array}$ \\
\hline & Understanding & $\begin{array}{l}\text { Understanding, learning, } \\
\text { knowledge acquisition, and/or } \\
\text { skill set development }\end{array}$ \\
\hline & Ego enhancement & $\begin{array}{l}\text { Self-enhancement via } \\
\text { acknowledgment, public } \\
\text { recognition, and/or self-esteem }\end{array}$ \\
\hline & Career & Career opportunities \\
\hline & Social & $\begin{array}{l}\text { Social relationships with like- } \\
\text { minded people and/or } \\
\text { connection to community }\end{array}$ \\
\hline & Protective & $\begin{array}{l}\text { Enjoyment and relaxation and/or } \\
\text { exercise in service of stress relief }\end{array}$ \\
\hline \multirow[t]{2}{*}{ Domain } & N/A & Natural science \\
\hline & & Nature/environment \\
\hline \multirow[t]{2}{*}{ Situational } & N/A & Getting outside \\
\hline & & Project-specific attributes \\
\hline
\end{tabular}

Notwithstanding the functionalist approach, many researchers have recognized motivation as an elusive, ill-defined concept and have thus attempted to operationalize motivation as a special form of interest, which itself has a long and varied history as an explanatory concept in psychology and social psychology (Deci and Ryan 1986, Krapp et al. 1992, Hidi and Renninger 2006). Krapp (1993, 1999, 2002), in particular, proposed a model of interest incorporating the psychology of individuals within their social and cultural contexts that we have adopted. Krapp and colleagues (Schiefele et al. 1983, Krapp 2002) conceptualized interest in terms of three interacting and interdependent components: the object(s) of interest, e.g., science; the action(s) of interest, e.g., help or contribute to science; and features of the persons themselves, e.g., identifies as a citizen scientist. "Personobject theory of interest" (hereafter POI; Krapp 2005) may allow for a more nuanced examination of the relationships between the "what" (i.e., object), "how" (i.e., action), and "who" (i.e., sense of self) shaping motivation in adult citizen science activity. Because objects and actions are often paired, they can also be nested within the categories of structural functionalism listed previously.

Individuals join volunteer activities for different, and often multiple, reasons (Katz 1960, Clary and Snyder 1999, Krapp 2005 , Bruyere and Rappe 2007). However, only those whose interests are satisfied by the activity remain (Clary and Snyder 1999), effectively narrowing the range of interests of the persisting population. One consequence of this winnowing process is that the persisting population may come to more closely match the values and tenets of the organization and each other (Clary and Snyder 1999, Carballo-Cárdenas and Tobi 2016). A cultural- historical approach explains this matching by suggesting that persisting individuals develop situational identities tied to the program (Wenger 1998, Engström 2009) and begin to adopt the goals or values of the program as their own (Stetsenko and Arievitch 2004, Stetsenko 2005). Within this paradigm, the connections between sense of self, development of interest, and the volunteered activity are reframed such that identities are embedded within, and emerge from, involvement with the work and with other participants (Penuel and Wertsch 1995). Finally, Rotman et al. (2012) suggest that individuals joining citizen science programs tend to start out with a higher degree of selfinterest (egoism), shifting their interests with deepened engagement toward attention to benefits for others (altruism), including nonhuman others, e.g., animals, nature, and the environment, in line with the values of the particular program for which they volunteer.

Collectively, these approaches to the study of volunteer motivation suggest that participants joining a hands-on, environmental citizen science program should initially be motivated by self-interest regarding objects of specific interest to them (Krapp 2002, Rotman et al. 2012), including seeking opportunities to gain knowledge and understanding and to develop skill sets connected to the environment and nature (Ryan et al. 2001, Bruyere and Rappe 2007, Domroese and Johnson 2017). These individuals should also seek a degree of social interaction within the activity (Stetsenko 2005), perhaps defined by friends, family, and like-minded others (Asah and Blahna 2013). By contrast, individuals who have participated in a program for some period of time may espouse relatively stronger altruistic motivations, including a desire to give back to the community, help the environment, and contribute through collective action to science, for instance (Busser and Norwalk 2001, Caissie and Halpenny 2003, Rotman et al. 2012, LandZandstra et al. 2016), and/or adopt new interests realized as a consequence of participation (Carballo-Cárdenas and Tobi 2016). Underlying this evolution, continuing participants should increasingly match the mission and goals of the program (Clary and Snyder 1999, Stetsenko and Arievitch 2004), coming to identify themselves relative to their roles in the activity (Stetsenko 2005). Finally, individuals realizing that their values do not coincide with the work or goals of the program, or feeling that they are not being sufficiently recognized, should withdraw their participation (Katz 1960, Rotman et al. 2012, Frensley et al. 2017).

We explore the motivations to recruit to, and be retained in, an outdoor, hands-on citizen science program, the Coastal Observation and Seabird Survey Team (COASST; Parrish et al. 2017), as a function of level of participant engagement, measured as time in program. We frame our study in POI, specifically qualitative coding for objects of interest, actions related to those objects, and senses of self, and then map those findings back onto the more generalized categories within structured functionalism. Given existing work, we predicted the following across the participating populations, i.e., newly engaged versus those engaged for more than 1 year:

- Interest should narrow. New participants should espouse a wider range of objects and actions of interest, and of senses of self, than seasoned participants. 
- Interest should match. With continued engagement, participants should adopt a stronger connection to program goals and values.

- Interest should shift. With continued engagement, participants should move from self-interest toward altruism.

Our study is one of only a handful of longitudinal studies examining motivations of adult citizen science participants engaged in hands-on, outdoor, environmental activities (see also Domroese and Johnson 2017, Pagès et al. 2018, Phillips et al. 2019), and it is one of the first to concomitantly explore situated sense of self. Such studies are increasingly needed given the explosive growth in biodiversity citizen science (Theobald et al. 2015), where a trained corps of continuing participants can become an informed voice for conservation (Haywood et al.2016).

\section{METHODS}

\section{Coastal Observation and Seabird Survey Team program}

COASST is a 19-year-old citizen science program principally focused on beach-cast marine birds as environmental indicators of nearshore marine health. As of 2018, the program had serially recruited $\sim 4500$ participants throughout coastal northern California, Oregon, Washington, and Alaska, with $\sim 800$ currently active in the beached bird program. After a 5-hour, expert-led training, attendees may elect to sign up for the program by agreeing to survey "their beach" on a monthly basis, collecting data on the abundance, condition, and identification of bird carcasses. Species identifications are verified by experts, and data are used in a wide range of scientific and natural resource management outlets (Parrish et al. 2017). Stories of data usage are also conveyed to participants through extensive web-based and in-person communications.

\section{Sample size and demographics}

We used answers to two free-write questions ("Why did you join COASST?"/"Why do you continue to be involved in COASST?") from assessment questionnaires delivered to both "new" and "seasoned" COASST participants, respectively, during the course of two separate research programs initiated in 2012 and 2016 and conducted under University of Washington Institutional Review Board protocols 37516 and 47963 (see Appendix 1 for complete question text; see Haywood et al. [2016] for details on assessment design). New participants were defined as attendees to an introductory training who filled out the assessment questionnaire. Seasoned participants were defined as individuals who had been actively collecting program data for at least a year at the time of our study.

Over 41 months and 60 trainings, 310 new participants elected to complete assessment questionnaires ( $71 \%$ return rate). Seasoned participants received questionnaires via mail resulting in 623 completed questionnaires (68\% return rate). However, 104 seasoned participants answered both 2012 and 2016 versions, respectively, because they were continuously active in the program over that entire period of time. For this specific seasoned participant subpopulation, we only used 2012 data, creating a final data set of 519 "unique seasoned participants." Because all questions were optional, final sample sizes for each question were lower than the responding population in total (new: $\mathrm{N}=299$; seasoned: $\mathrm{N}=462$ ).
Across new and unique seasoned participant populations that answered either of the relevant questions on the assessment questionnaire, and that chose to provide demographic information, female was the dominant gender (new: $69 \%, \mathrm{~N}=$ 271; seasoned: $63 \%, \mathrm{~N}=431$ ). Average age at training was 52 years $(\mathrm{SD}=16.4 ; \mathrm{N}=240)$ for new participants, slightly younger than that of seasoned participants $(57 \pm 19.9 ; \mathrm{N}=365)$. At the time of the assessment, the average length of participation for seasoned participants was 4.5 years $(\mathrm{SD}=2.7$; $\mathrm{N}=411$ ). Selfassessed level of bird experience revealed that most participants did not consider themselves as birders (advanced + expert: $12 \%$, $\mathrm{N}=250$ [new]; 19\%, $\mathrm{N}=367$ [seasoned]).

\section{Data production}

We developed a codebook for analysis of the free-write answers based on existing literature on the interests and motivations of adult participants in environmental monitoring programs (e.g., Bruyere and Rappe, 2007, Asah and Blahna 2013, Land-Zandstra et al. 2016, Ganzevoort et al. 2017) and previous studies of COASST participants (Haywood 2014, Haywood et al. 2016), using POI (Krapp 2005) as a framework (see Appendix 2 for codes and examples), as follows:

- Interest: defined both relative to discrete objects the participants described their interest in interacting with, e.g., birds and science, and the actions embodied by that interest, e.g., learning and helping. Objects and actions were not necessarily paired, e.g., learning about birds, but all cooccurrences were encoded. In addition, we coded a simple measure of intensity that we refer to as importance, defined by participants' explicit use of the terms "valuable," "worthwhile," "meaningful," and/or "important," with respect to their objects and/or actions of interest.

- Sense of self: defined as description of and feelings about the self. Sense of self included identities relative to the program, both explicit, e.g., "I am a birder" names the identity birder, and implicit, e.g., "I like to watch my son identify the birds" implies a familial identity. We also coded self-esteem, defined as feeling useful, needed, proud, or good about themselves, e.g., "seems like a good way to make me feel useful," often within the context of a particular action and/or action-object pair.

A diagrammatic representation of our POI approach to free-write coding is shown in Figure 1. Note that within any one respondent, single to multiple objects and/or actions and/or senses or self could be apparent; co-occurrence across object-action pairs was possible but not a prerequisite; and across an entire respondent population, i.e., new and seasoned, a frequency distribution of objects, actions, and senses of self, as well as object-action cooccurrences, emerged. This approach allowed us to map objectaction interests back onto functions (sensu Clary and Snyder 1999) structured as basic, domain specific, and situation specific (i.e., Table 1), as well as explore the situational identity (Vryan 2007), or "role" within the socio-cultural activity system (Engström 2000, Roth et al. 2009) that is COASST, e.g., that of data collector.

Two authors (He and Parrish) independently conducted 5 rounds of pilot coding (145 respondent answers in total). Discrepancies were discussed to reach consensus and associated refinement of the coding scheme. At 78\% agreement and no further refinements 
Fig. 1. Coding schema for person-object theory of interest presented diagrammatically with example quotes from four actual Coastal Observation and Seabird Survey Team (COASST) participants: two from new participants (attended training) and two from seasoned participants (1 year plus of data collection). Sense-ofself codes are categorized into three overlapping identity codes: social identity, science identity, and individual attributes (see Fig. 4). Actual coding is shown by black arrows. Not all participants articulated objects, actions, and/or sense of self, respectively. Ellipses indicate additional codes omitted for visual clarity (see Figs. 2 and 4 for full list and Appendix 2 for codebook).

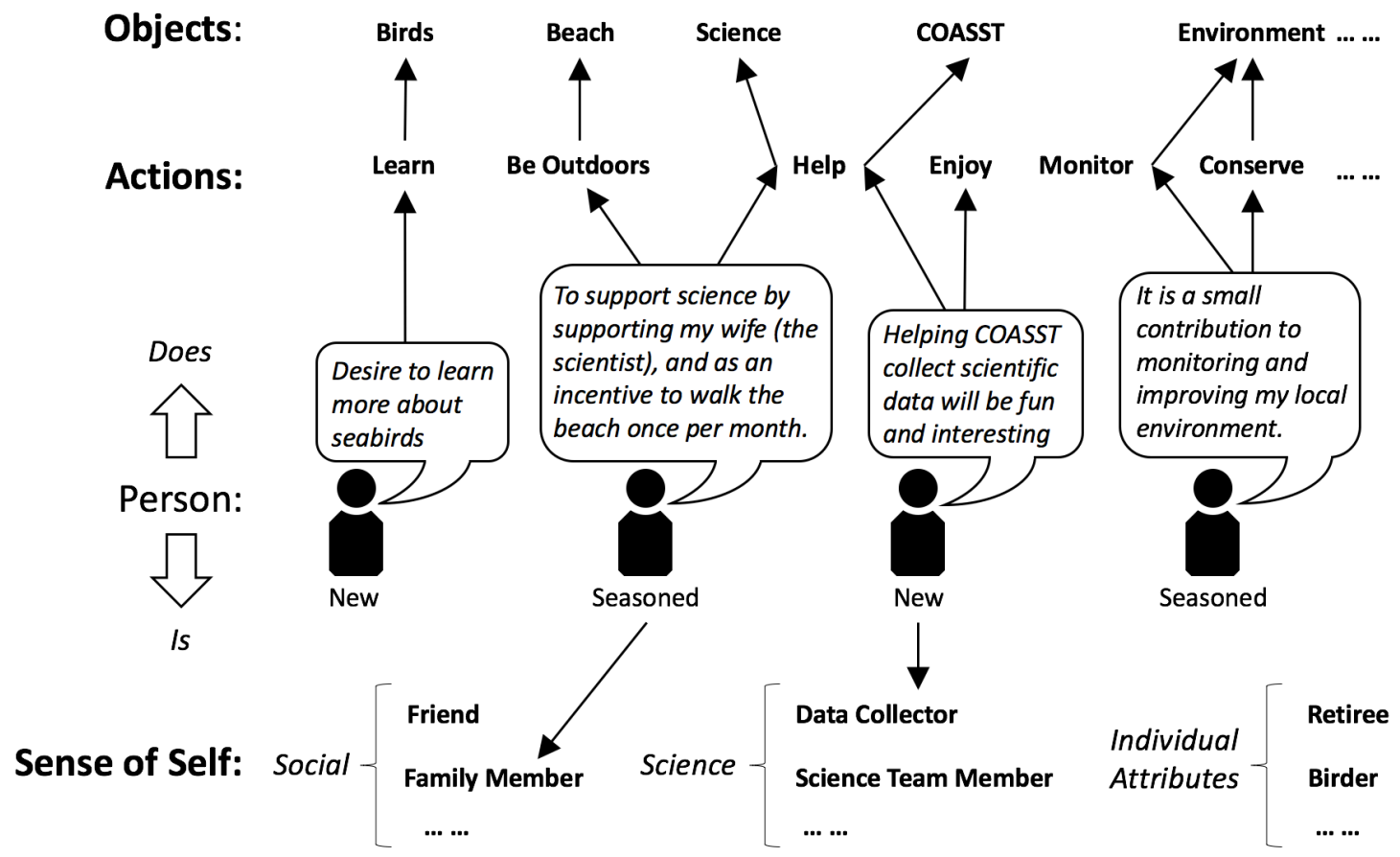

to the codebook, pilot coding stopped, and one author $(\mathrm{He})$ coded all 761 responses (Dedoose Version 7.6.6). For all codes, we calculated the frequency of occurrence within the respondent population. For the 3 most frequent object and action codes, respectively, we calculated the percent of co-occurrence with all action (object) codes, i.e., object-action pairs. Co-occurrence was also used to explore the degree to which participants assigned importance to objects or actions. To simplify presentation, we created minimum thresholds at the population level, i.e., new and seasoned, for inclusion in our graphics (objects and actions: $3 \%$; sense of self: $1 \%$ ).

To independently assess situational identity, we also used a question only found on the 2016 assessment explicitly exploring roles and tasks within the program (see Appendix 1 for complete question text). Note that this data set adds back "duplicate" seasoned participants between 2012 and 2016 and who elected to answer the question $(\mathrm{N}=104)$. This question asked participants to decide whether they thought they would be (new), or were or wanted to be (seasoned), engaged in a series of 17 named tasks that collectively frame and define the science process within the COASST program. New participants $(\mathrm{N}=166)$ were asked to select tasks they imagined they might be doing in COASST based on their knowledge/experience of other citizen science or science programs. Seasoned participants $(\mathrm{N}=305)$ selected all tasks they did perform, as well as tasks they were not performing but wished to perform. In both questionnaires, participants were told that tasks could be assigned to other roles, e.g., COASST staff or partner scientists, or left unassigned.

\section{Statistical analysis}

We used Z-tests at the code level to determine whether differences as a function of engagement discernible by year (i.e., 2012 vs. 2016) were conserved in the combined data set (i.e., 2012 + 2016). Out of 39 codes tested, only 2, i.e., "greater good + worldview" and "citizen scientist," lost their significance in the pooled data set (see Table A3.1 in Appendix 3). As these 2 codes were also infrequent $(<10 \%$ of the responding population), we opted to combine our data across years, which improved sample size and allowed us to focus on the effect of engagement.

For the combined data set, we used chi-square contingency tables to compare code occurrence between new and seasoned respondent populations. To assess whether there was a narrowing of object, action, or sense-of-self code diversity between new and seasoned populations, we used the Simpson index of diversity $(D)$, which accounts for both code occurrence and the relative frequency (or evenness) of codes. The Simpson index is relatively sensitive to changes in the dominance of a particular type, i.e., frequent response codes, and comparatively less sensitive to rarity (Buckland et al. 2005). Within each interest category, and for each code, denoted by $i$, we calculated the frequency of 
occurrence, $p_{i}$, according to:

$$
p_{i}=\frac{N_{i}}{\sum_{j}^{n_{\text {code }}} N_{j}}
$$

where $N_{i}$ is the number of times code $i$ was recorded and $n_{\text {code }}$ is the number of unique codes. The Simpson index, $D$, was then calculated as follows:

$$
D=1-\sum_{i}^{n_{\text {code }}} p_{i}^{2}
$$

To quantify variability, we used a bootstrap resampling approach (1000 permutations), standardized for sample size differences, whereby responses were resampled at random with replacement to generate a distribution for and subsequently processed to extract a $95 \%$ confidence interval (CI). Note that combining data across years improved the absolute number of rare codes.

\section{RESULTS}

\section{Objects and actions}

Among the 9 object categories named by greater than 3\% of any respondent population, birds and beach were the most frequently mentioned (Fig. 2). New participants focused on the organism more often (birds: $\chi^{2}=11.08, \mathrm{df}=1, \mathrm{p}=0.0009$ ), whereas seasoned participants tended to focus more on place (beach: $\chi^{2}=8.94$, df $=1, p=0.0028)$. Among less frequent responses, new participants referred more often to their interests in nature and the environment $\left(\chi^{2}=7.26, \mathrm{df}=1, \mathrm{p}=0.0070\right)$ and to citizen science $\left(\chi^{2}=5.99, \mathrm{df}=1, \mathrm{p}=0.0144\right)$, whereas seasoned participants referred more to COASST itself $\left(\chi^{2}=11.03, \mathrm{df}=1, \mathrm{p}=0.0009\right)$. Because the code "COASST" covered a wide range of interests, we subdivided this object into 3 more specific codes: the COASST "program" including its structure, organization, personnel, and materials; the value and usage of "data and results" produced by the program as a whole versus the data an individual participant collected; and the physical "practice" of the COASST protocol on the beach. Although seasoned participants displayed increased interests relative to new participants across almost all comparisons, this trend was most dramatic with respect to COASST data and results $\left(\chi^{2}=16.82, \mathrm{df}=1, \mathrm{p}<0.0001\right)$.

Similar to the distribution of object codes, 2 of the 7 action codes were paramount: being outdoors, referred to more often by seasoned participants $\left(\mathrm{x}^{2}=8.72, \mathrm{df}=1, \mathrm{p}=0.0031\right)$; and helping/ contributing, a code equally referred to by both populations. Within less frequent, but still relatively common actions, new participants mentioned learning much more frequently than did seasoned participants $\left(\chi^{2}=8.95, \mathrm{df}=1, \mathrm{p}=0.0028\right)$, and the opposite was true of monitoring/observing $\left(\chi^{2}=14.97, \mathrm{df}=1, \mathrm{p}\right.$ $=0.0001)$. Of infrequent responses, seasoned participants referred more frequently to having fun/enjoyment $\left(\chi^{2}=6.44\right.$, $\mathrm{df}=1, \mathrm{p}=$ $0.0112)$ and preserving health $\left(\chi^{2}=5.06, \mathrm{df}=1, \mathrm{p}=0.0244\right)$.

To more readily investigate $\mathrm{POI}$, we explored co-occurrence among the 3 most frequently mentioned objects, i.e., beach, birds, and COASST, and actions, i.e., being outdoors, help/contribute, and learn, respectively, and all other nontrivial action (object) codes. Co-occurrence reveals the relative strength of association
Fig. 2. The percent of survey respondents expressing objects (top) and actions (bottom) of interest. Participant populations (new, seasoned) as in Figure 1. All objects and actions are categorized as falling into one of three functional types: basic (B), domain-specific (D), or situational (S). Actions relevant to self-interest or altruism are signified by superscripts SI and A, respectively. Asterisks indicate the level of significance for chisquare contingency table tests (new vs. seasoned): ${ }^{*} \mathrm{p}<0.05$; ** $\mathrm{p}<0.01$. See text for sample sizes and Appendix 1 for question wording. COASST, Coastal Observation and Seabird Survey Team.

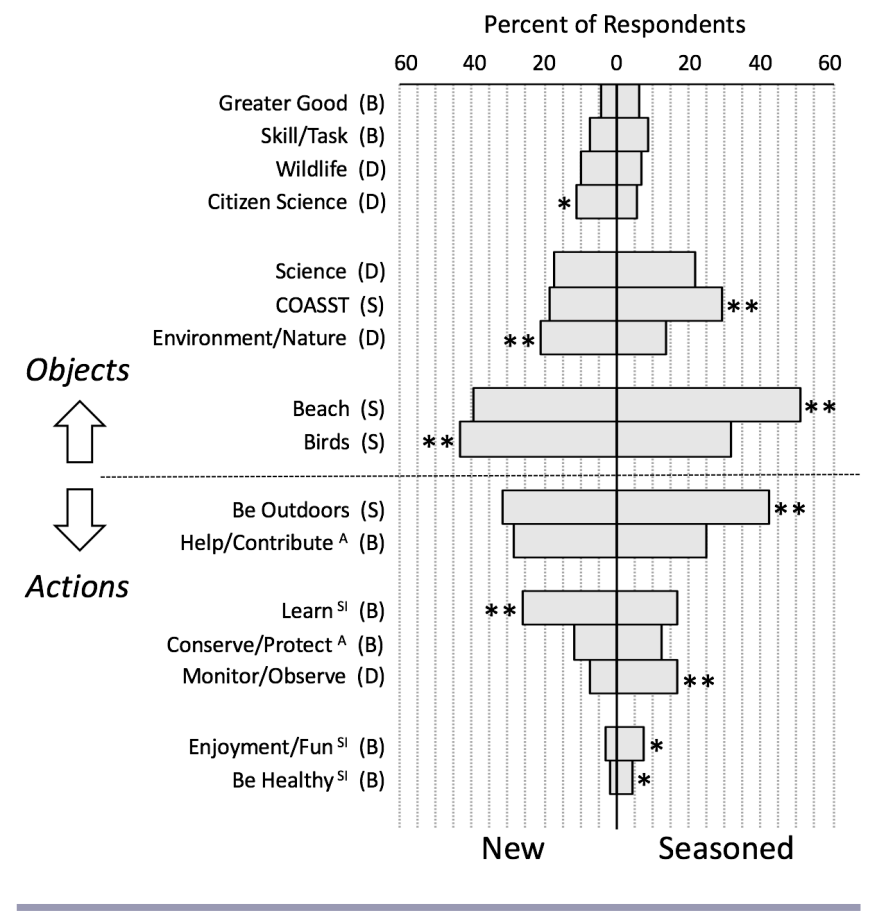

between any given object-action pair, regardless of whether there was a change in the overall response rate of the underlying object or action (i.e., Fig. 2). The strongest connection for both new and seasoned participants was between "beach" and "being outdoors" (Tables 2 and 3), with all other beach*action, and being outdoors* object, pairings accounting for less than $20 \%$ of the relevant responding population, with most less than $10 \%$. "Birds" was most strongly associated with the desire to learn, and vice versa, in both new and seasoned participants (Tables 2 and 3). This association was constant despite the drop in "learn" as a function of engagement (i.e., Fig. 2). There was a lesser association between "learn" and "environment/nature," which weakened as a function of engagement (learn*environment/nature: $\chi^{2}=4.13$, df $=1, \mathrm{p}=$ 0.0421; Table 3). Relative to new participants, seasoned COASST members associated "beach" and "birds" with "monitoring/ observing" much more frequently (beach*monitor: $\chi^{2}=14.13$, df $=1, \mathrm{p}=0.0002$; birds*monitor: $\chi^{2}=4.95, \mathrm{df}=1, \mathrm{p}=0.0261$; Table $2)$. The action "help/contribute" was principally focused on "science," and this association was intensified for seasoned participants (help*science: $\chi^{2}=7.84, \mathrm{df}=1, \mathrm{p}=0.0051$; Table 3 ), despite the equality of the underlying action response (i.e., Fig. 2). 
Table 2. Co-occurrence of object*action codes, limited to the three most prevalent object codes: beach, birds, and COASST (see Fig. 2). Data are percent of respondents mentioning the relevant object (columns) and the corresponding action (rows) organized from larger to smaller percentages. Results are shown only for co-occurrences above a 3\% response minimum for any single co-occurrence. Sample sizes are respondent counts. Statistically significant comparisons (new vs. seasoned; chi-square contingency tables) are bolded for clarity. Asterisks indicate the level of significance: ${ }^{*} \mathrm{p}<0.05 ; *{ }^{*} \mathrm{p}<0.01$. COASST, Coastal Observation and Seabird Survey Team.

\begin{tabular}{|c|c|c|c|c|c|c|}
\hline \multirow{2}{*}{$\begin{array}{l}\text { Objects: } \\
\text { Actions: }\end{array}$} & \multicolumn{2}{|c|}{ Beach } & \multicolumn{2}{|c|}{ Birds } & \multicolumn{2}{|c|}{ COASST } \\
\hline & $\begin{array}{c}\text { New } \\
(\mathrm{N}=119)\end{array}$ & $\begin{array}{l}\text { Seasoned } \\
(\mathrm{N}=235)\end{array}$ & $\begin{array}{c}\text { New } \\
(N=130)\end{array}$ & $\begin{array}{l}\text { Seasoned } \\
(\mathrm{N}=146)\end{array}$ & $\begin{array}{c}\text { New } \\
(\mathrm{N}=56)\end{array}$ & $\begin{array}{l}\text { Seasoned } \\
(\mathrm{N}=136)\end{array}$ \\
\hline Be outdoors & $56.3 \%$ & $62.1 \%$ & $4.6 \%$ & $5.5 \%$ & $1.8 \%$ & $3.7 \%$ \\
\hline Learn & $7.6 \%$ & $6.0 \%$ & $23.1 \%$ & $23.3 \%$ & $10.7 \%$ & $3.7 \%$ \\
\hline Monitor/observe & $3.4 \%$ & $17.4 \% * *$ & $3.8 \%$ & $11.0 \% *$ & $5.4 \%$ & $14.7 \%$ \\
\hline Conserve/protect & $4.2 \%$ & $8.5 \%$ & $8.5 \%$ & $11.0 \%$ & $1.8 \%$ & $4.4 \%$ \\
\hline Help/contribute & $4.2 \%$ & $4.3 \%$ & $4.6 \%$ & $8.2 \%$ & $10.7 \%$ & $7.4 \%$ \\
\hline Enjoyment & $0.0 \%$ & $3.8 \%$ & $1.5 \%$ & $2.7 \%$ & $7.1 \%$ & $6.6 \%$ \\
\hline
\end{tabular}

Although "COASST" was not usually mentioned with a specific action, it was more frequently connected with "importance" than any other object of interest (Fig. 3). In fact, frequent objects and actions (i.e., $>30 \%$ of respondents) were rarely labeled as important (i.e., upper right quadrats of Fig. 3 panels are empty). Instead, importance was most often assigned to relatively infrequent objects (i.e., $<30 \%$ of respondents) and especially to COASST and its data and results. As a group, seasoned participants tended to elevate all codes referred to as important, with COASST data/results reaching well above the $30 \%$ threshold (Fig. 3).

Fig. 3. The co-occurrence of interest (objects: gray circles; actions: white circles) and importance, scaled equally across new and seasoned populations. The horizontal axis is the percent of the relevant responding population expressing a particular interest code; the vertical axis is the percent of that interest code population identifying the action or object as important. Interests in high frequency or importance quadrats are individually identified. COASST, Coastal Observation and Seabird Survey Team.

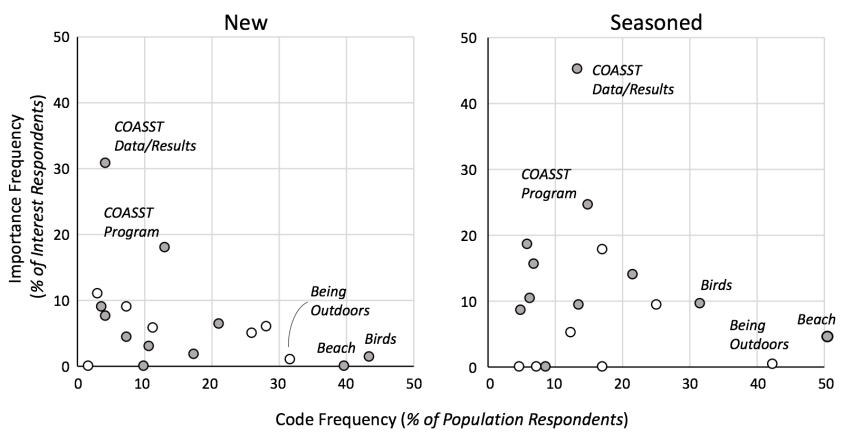

Objects and actions: narrow, match, and shift

Based on the literature, we predicted that interests would narrow and become increasingly aligned with the values and goals of the program as a function of engagement, i.e., from the new to the seasoned population, and that there would be a concomitant shift from self-interested motivations to altruistic ones. We used the Simpson diversity index to investigate the effect of engagement on the range of respondent interests, where higher numbers indicate more codes at a given population size. There was no significant difference in object code diversity as a function of engagement (new: $D=0.84,95 \%$ CI $0.83-0.85$; seasoned: $D=$ $0.83,95 \%$ CI $0.82-0.84$ ). For actions, there was actually significant increase in diversity, the opposite of our prediction (new: $D=$ $0.82,95 \%$ CI $0.80-0.83$; seasoned: $D=0.85,95 \%$ CI $0.84-0.86$ ).

To investigate the population tendency to match the goals and values of the program, we tracked changes in the frequency of science-based codes, including the objects "science" and "COASST," the action "monitor/observe," and the co-occurrence of importance with these codes. Seasoned participants mentioned the object "COASST" and the action "monitoring/observing" significantly more than new participants (Fig. 2). They also intensified science-oriented action*object pairs: monitor/observe with both beach and bird ( $3-5$ times over new participants; Table $2)$ and help/contribute with science $(\sim 2$ times over new participants; Table 3). Finally, they increased their tendency to label COASST data/results as important (Fig. 3). Collectively, this suggests that seasoned participants may be adopting program products and practices into their motivations to participate.

Finally, to explore shifts from self-interest to altruism, we labeled the actions "learn," "enjoyment/fun," and "be healthy" as those representing self-interest, and "help/contribute" and "conserve/ protect" most representative of altruism (Fig. 2). Across these five codes there was no coherence, as shifts in both directions, that is, away from self-interest, i.e., decline in learning, and toward selfinterest, i.e., increase in enjoyment/fun and being healthy and decline in help/contribute, were both apparent.

\section{Sense of self: identities, roles, and self-esteem}

The open-ended assessment questions did not ask participants to describe themselves; however, about half (42\%-49\%) of the participants volunteered information about themselves within the context of COASST. We coded these statements as expressions of a COASST "sense of self" and categorized them a posteriori into 3 broadly overlapping identities: social identity, or participants' relationships with other people in the COASST program; science identity, or the tasks, roles, and formal credentials directly related to science, including within COASST; and individual attributes, or descriptions of personal accomplishments or states of being (Fig. 4). Note that at the code 
Table 3. Co-occurrence of object*action codes, limited to the three most prevalent action codes: be outdoors, learn, and help/contribute (see Fig. 2). All other formatting as in Table 2. COASST, Coastal Observation and Seabird Survey Team.

\begin{tabular}{|c|c|c|c|c|c|c|}
\hline \multirow{2}{*}{$\begin{array}{l}\text { Actions: } \\
\text { Objects: }\end{array}$} & \multicolumn{2}{|c|}{ Be Outdoors } & \multicolumn{2}{|c|}{ Learn } & \multicolumn{2}{|c|}{ Help/Contribute } \\
\hline & $\begin{array}{c}\text { New } \\
(\mathrm{N}=95)\end{array}$ & $\begin{array}{l}\text { Seasoned } \\
(\mathrm{N}=196)\end{array}$ & $\begin{array}{c}\text { New } \\
(\mathrm{N}=78)\end{array}$ & $\begin{array}{c}\text { Seasoned } \\
(\mathrm{N}=79)\end{array}$ & $\begin{array}{c}\text { New } \\
(\mathrm{N}=84)\end{array}$ & $\begin{array}{l}\text { Seasoned } \\
(\mathrm{N}=116)\end{array}$ \\
\hline Beach & $70.5 \%$ & $74.5 \%$ & $11.5 \%$ & $17.7 \%$ & $6.0 \%$ & $8.6 \%$ \\
\hline Birds & $6.3 \%$ & $4.1 \%$ & $38.5 \%$ & $43.0 \%$ & $7.1 \%$ & $10.3 \%$ \\
\hline Science & $4.2 \%$ & $1.5 \%$ & $2.6 \%$ & $3.8 \%$ & $20.2 \%$ & $38.8 \% * *$ \\
\hline Skill or task & $4.2 \%$ & $1.0 \%$ & $14.1 \%$ & $24.1 \%$ & $1.2 \%$ & $1.7 \%$ \\
\hline Environment/nature & $2.1 \%$ & $3.6 \%$ & $16.7 \%$ & $6.3 \% *$ & $9.5 \%$ & $12.1 \%$ \\
\hline COASST & $1.1 \%$ & $2.6 \%$ & $7.7 \%$ & $6.3 \%$ & $7.1 \%$ & $8.6 \%$ \\
\hline Greater good & $1.1 \%$ & $0.5 \%$ & $3.8 \%$ & $0.0 \%$ & $4.8 \%$ & $8.6 \%$ \\
\hline Citizen science & $1.1 \%$ & $0.0 \%$ & $1.3 \%$ & $0.0 \%$ & $7.1 \%$ & $1.7 \%$ \\
\hline Wildlife & $4.2 \%$ & $1.0 \%$ & $2.6 \%$ & $1.3 \%$ & $1.2 \%$ & $1.7 \%$ \\
\hline
\end{tabular}

level, elements of identity overlap; e.g., "survey team member" is both social identity and science identity. We coded self-esteem separately.

Fig. 4. Percent of survey respondents expressing senses of self as a function of engagement (new, seasoned). Formatting as in Figure 2. Two-headed lines at left depict three overlapping situational identities with respect to participants in the Coastal Observation and Seabird Survey Team program: social, science, and individual attributes.

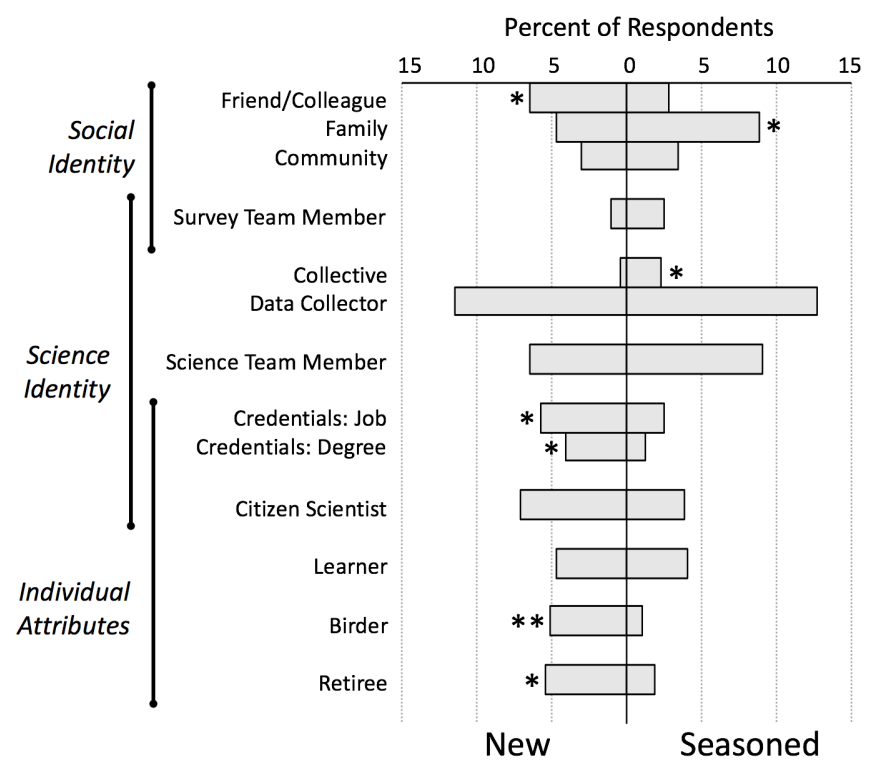

Participants often described COASST as a social activity, or something to do with friends and family and survey team partner (s) and/or as a part of the community (Fig. 4). Seasoned participants tended to talk more about their family $\left(\chi^{2}=4.76\right.$, df $=1, \mathrm{p}=0.0292)$ and less about their friends $\left(\chi^{2}=5.56, \mathrm{df}=1, \mathrm{p}\right.$ $=0.0175)$. Within science identity, the roles of data collector and science team member were the most prevalent codes, among the most prevalent sense-of-self codes overall, and statistically invariant between new and seasoned populations (Fig. 4). However, within science identity, several codes did change significantly among participant populations. Seasoned participants referred more often to being part of a larger effort composed of many individuals all engaged in the same thing (collective: $\chi^{2}=$ 4.90 , $\mathrm{df}=1, \mathrm{p}=0.0269$ ). By contrast, new participants talked more about themselves, including holding scientific jobs $\left(\chi^{2}=\right.$ 4.72, $\mathrm{df}=1, \mathrm{p}=0.0298)$ and possessing degrees $\left(\chi^{2}=5.79, \mathrm{df}=\right.$ $1, p=0.0161)$. In fact, except for "citizen scientist" and "learner," all other forms of individual attribute description, including those less directly associated with science, decreased markedly as a function of engagement (birder: $\chi^{2}=10.98$, df $=1, p=0.0009$; retiree: $\chi^{2}=6.62$, df $=1, p=0.0101$; Fig. 4). Finally, seasoned participants registered a significant increase in self-esteem relative to new participants (from $7 \%$ to $16 \%, \chi^{2}=13.44$, df $=1, p=$ 0.0002 ), and this was largely tied to their actions in, and for, the program.

\section{Sense of self: roles and tasks}

To more explicitly explore situational identity, we included a question in our 2016 assessment asking respondents to select all of the scientific tasks they imagined they would be doing (new) or were doing or wanted to do (seasoned). Relative to answers given by seasoned participants, the new participant population overestimated their future involvement in almost all tasks, excepting collect data, make measurements, and enter data $\left(\chi^{2}=\right.$ various, $\mathrm{df}=1, \mathrm{p}<0.0005$; Fig. 5; see Table A3.2 in Appendix $3)$. However, when tasks were ranked by frequency of response (e.g., Fig. 5, light gray), the top 4 tasks were coincident across new and seasoned populations. A fifth task, enter data, was equally frequent across new versus seasoned ( $\sim 50 \%$ of respondents) but was ranked slightly lower (eighth) by new participants.

Seasoned participants did not seem to miss these "lost" opportunities, because the percentage of respondents checking "don't now do but want to do" was frequently under 5\% (Fig. 5, dark gray). Only 2 tasks, interacting with scientists and interacting with resource managers, might be interpreted as something participants remained desirous of, because these were initially highly ranked by new participants (fifth and seventh) and received the largest frequency of "want to do" responses by seasoned participants (> 10\%; Fig. 5, dark gray).

\section{Sense of self: narrow and match}

Within sense of self, we found strong support for both predictions that situational identity should narrow and become more aligned 
with the goals and values of the program. Across all identity codes, the Simpson diversity index dropped significantly from new to seasoned participants (new: $D=0.92,95 \%$ CI 0.91-0.92; seasoned: $D=0.89$, 95\% CI 0.88-0.91), reflecting the move away from individual attributes and toward science and social identities. Narrowing toward science was also apparent in the task responses (Fig. 5), albeit also mixed with a strong sense of social interaction. In sum, these responses suggest that seasoned participants interpreted their role as both fulfilling basic scientific tasks necessary in COASST, i.e., data collector (taking measurements and collecting and entering data), and social tasks helping to sustain the program, i.e., participating with family, communicating results, and recruiting others.

Fig. 5. Distribution of tasks within the Coastal Observation and Seabird Survey Team program as a function of engagement: new participants (light gray indicates "will do"); seasoned participants (light gray indicates "currently perform"; dark gray indicates "want to do"). Asterisks indicate significant differences $(p<0.01)$ for chi-square contingency table tests comparing new and seasoned participants, i.e., new (will do) versus seasoned (currently perform). See Appendix 3 for statistical values and additional comparisons.

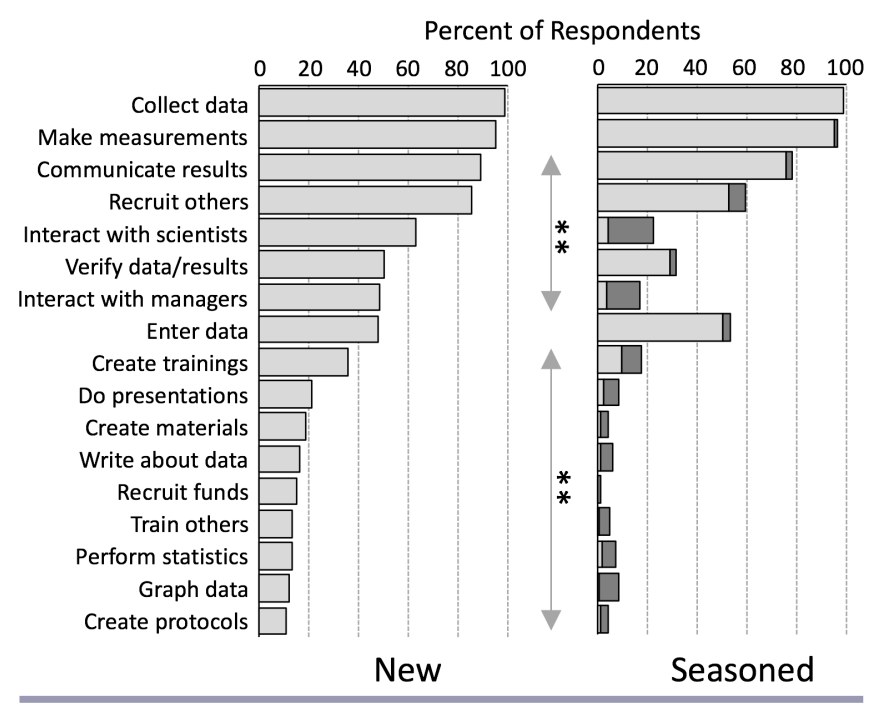

\section{DISCUSSION}

As one of the few longitudinal studies within environmental citizen science (and see Domroese and Johnson 2017, Pagès et al. 2018, Phillips et al. 2019), our study begins to uncover how the motivations of adult free-choice learners can change as a function of their engagement level, where motivation captures both the interests, i.e., objects, actions, and object:action pairs (sensu Krapp 2002), and senses of self or situational identity (Stetsenko 2005, Vryan 2007) of the participants.

\section{Mapping person-object theory of interest to structured functionalism}

We have proposed a structured "environmental approach" to functionalism (sensu Katz 1960, Clary and Snyder 1999), which both interprets functions basic to volunteerism and adds domainand situation-specific functions (i.e., Table 1). Among all COASST participants in our study, actions largely mapped to basic functions, whereas objects almost exclusively mapped to domain- or situation-specific functions (Fig. 2; and see subsequent quotes). This suggests that basic, domain-specific, and situation-specific interests are not necessarily exclusive, but intertwined and complementary (see also Pagés et al. 2018).

Situational only: It's a great excuse to spend time on the beach! (Full answer, seasoned)

Basic, domain, and situational: It is important datal information necessary for baseline information as to what is "normal" in the event of natural or human caused disaster or changes in climate-such as ocean tempsfood supply or others. I like knowing I am making a small contribution to this effort, the oceans are our "life support" systems, birds are indicators of its health. (Full answer, seasoned)

Among basic functions, the function of "values" was well represented in the COASST participant corps, expressed as a desire to help with or contribute to science specifically, as well as to be involved in a program focused on conserving or protecting environmental and natural resources (Fig. 2, Table 3):

\section{I have an interest in seabird conservation and research. I want to help contribute to these fields through citizen science. (Full answer, new)}

It's an easy way for me to scientifically contribute, albeit in a small way, to the stewardship of the environment and thus, humanity. (Full answer, seasoned)

These findings align with other studies that have also found a strong values theme, including conservation or environmental concern (Jones et al. 2017), contributing to science (LandZandstra et al. 2016, Domroese and Johnson 2017), or simply doing something for the greater good (Miles et al. 2000).

The basic function "understanding," mostly expressed as interest in learning, was also well represented in our study, as participants espoused an interest in learning about birds, learning new skills, and learning about their beach and the environment more broadly (Fig. 2, Table 3):

I have learned, and continue to learn, so much about seabirds (their anatomy, etc.) and beach changes over time on the WA coast. (Excerpt, seasoned)

Although some form of understanding of the work, system, or science at hand is represented in most studies of environmental volunteerism, relatively few have reported learning as the dominant function (but see Domroese and Johnson 2017; ranked as second via Likert scoring: Ganzevoort et al. 2017).

Both "ego enhancement" and "social" functions were present in our coding, albeit not as prevalently as either values or understanding. Ego enhancement, expressed as self-worth associated with citizen science efforts, was nontrivial (to $16 \%$ of the responding population):

COASST is one of several types of bird-related citizen
science that I do. Citizen science projects are among the
most worthwhile, rewarding activities for me in
retirement. (Excerpt, seasoned)

Whether self-esteem is a widely subscribed function is unclear, because many studies do not appear to separate feelings of self- 
worth from the value-based functions of contributing to the greater good, as in the work being a "meaningful action" (Miles et al. 2000). Other forms of ego enhancement, including acknowledgement or public recognition, were undetected in our coding. By contrast, Phillips et al. (2019) found aspects of public recognition were widespread (40\% of respondents) among participants in 6 different environmental citizen science programs. Social functions of "volunteerism" and specifically conducting the work with like-minded others appear across a wide range of studies (see especially Asah and Blahna 2013, Pagés et al. 2018, Phillips et al. 2019). We found evidence of social interactions within our sense-of-self coding (Fig. 4), most specifically focused on those individuals that participants wanted to support, i.e., friends and family (see second quote in Fig. 1), and work with, i.e., survey team members:

\section{LOVE working as a volunteer and working with other volunteers even more. (Excerpt, new)}

The remaining basic functions, i.e., "career opportunities" and "protective interests," were present in our data, but only in a minor way. Given that the participating population in most biodiversity citizen science programs is largely adult and retired (Burgess et al. 2017), the lack of a career focus is understandable. Protective functions, including enjoyment, relaxation, and/or exercise, have only rarely occurred as a top function in other studies of environmental volunteerism (but see Wright et al. 2015). Within the COASST participant population, both enjoyment and health-related benefits (including both physical and mental health) were rarely mentioned (Fig. 2). However, both codes increased significantly in frequency in the seasoned participant population, suggesting that although these functions may not be primary motivators, they may be "unintended" benefits of continued activity.

\section{The effect of engagement: narrow, match, and shift}

Based on the empirical literature within environmental volunteerism, including citizen science, and the theoretical literature on activity theory (Stetsenko and Arievitch 2004), we constructed a series of three predictions regarding the influence of engagement, i.e., time in the program: Compared to the newly participating population, COASST participants with at least 1 year of experience in the program, i.e., seasoned participants, should have a narrower range of expressed motivations, which align more closely with, or match, those of the program, and which have shifted to a stronger sense of altruism relative to expressions of self-interest.

Both new and seasoned participants expressed the same suite of interests, i.e., actions and objects, which remained largely invariant in their relative ranking (Fig. 2). Narrowing of objects or actions was not substantiated. One interpretation of this finding is that incoming participants already had a good sense of the program, and their interest functions (sensu Clary and Snyder 1999) were largely accommodated. However, both senses of self (Fig. 4) and task self-assignment (Fig. 5) narrowed significantly from new to seasoned participant populations. Krapp (2002) posited that as the objects and actions of interest change, so should the sense of self. That is, a situational identity tied to the activity at hand should develop (Stetsenko and Arievitch 2004). Individuals new to COASST sought to define themselves with personal attributes culturally acknowledged as relevant to the activity at hand: birding expertise ("I am a birder"), scientific credentials ("I am a biologist by training"), and experience in informal science practice ("I am a citizen scientist"). Seasoned participants obviously remained in these roles in their lives but may have felt less need to be defined by them within COASST. Instead, they favored program-specific roles including member of a science team, member of the collective (sensu Halpenny and Caissie 2003, Haywood et al. 2016), and most especially data collector (Fig. 4). Phillips et al. (2019) suggest that participants in environmental citizen science become strongly attached to the role of hands-on data collector over other science tasks (see also Weston et al. 2003, Frensley et al. 2017).

We maintain that continued engagement did create a participant corps with expressed motivations that more closely matched the program, i.e., our second prediction. The program itself as a source of interest increased (Fig. 2), as did the fraction of the respondent population assigning importance to COASST data/ results (Fig. 3). Expressions of the work of science increased as well, including the desire to help or contribute to science (Table 3 ) and the use of specific scientific phrasing such as "monitor" and "observe" (Fig. 2, Tables 2 and 3). These findings echo Domroese and Johnson (2017) who found a doubling in the motivation "contributions to scientific research" from new to seasoned (assessed at end of their first year) participants in the Great Pollinator Program.

Our final prediction concerned the range of motivations indicative of a shift from self-interest to those more aligned with altruism (Rotman et al. 2012). Several studies of the motivations driving hands-on environmental volunteers have found strong self-interest themes, most prevalently acquiring knowledge and/ or sharpening skill sets (Caissie and Halpenny 2003, Domroese and Johnson 2017, Ganzevoort et al. 2017, Jones et al. 2017), but also including increasing career opportunities, having fun, and receiving recognition and other egoist accolades (Clary and Snyder 1999, Bruyere and Rappe 2007, Asah and Blahna 2013). Strong altruistic themes, prominently including helping/ contributing and conservation, are also apparent across the environmental volunteerism literature (Land-Zandstra et al. 2016, Frensley et al. 2017). Although participants new to COASST emphasized their desire to learn relative to seasoned participants (Fig. 2), they also espoused a range of actions more aligned with altruism, including most prominently their desire to help or contribute to science and to the environment (Fig. 2, Table 3). Seasoned participants were similarly multidimensional in their functional interests:

\section{I find the surveys enjoyable and interesting. I love being outside, hiking the beaches, learning something new each time, exploring, and, hopefully, supporting the work that COASST is doing. (Full answer, seasoned)}

These results suggest that participant motivations, at least at the population level, are more complex than a simple shift from selfinterest to altruism.

\section{Science is a social activity}

Within an activity theory construct, Stetsenko and Arievitch (2004) and Stetsenko (2005) point to the "ineluctably social" nature of communities collectively accomplishing work (for our study, the "activity" COASST science). Pagés et al. (2018) refer 
to these interactions as conviviality. Our findings that social identity factors including family and friends and, more generally, survey team members were motivators for joining and/or remaining active in the program (Fig. 4) support this sociocultural construct. Whether the shift from friend-dominant to family-dominant between new and seasoned participant populations in COASST holds social significance is unknown but does suggest that friends may instigate joining, whereas participants who recruit as, or subsequently recruit, family members are more likely to persist. Regardless, COASST participants clearly understood the program to be social. The third most common task response in both new and seasoned populations was communicating results, and the fourth most common was recruiting others (Fig. 5):

Over the years we've gathered a crew of people who often come with us so it has become a social event. (Excerpt, seasoned)

Asah and Blahna (2013) also found that interactions with friends, family, and like-minded people were overwhelmingly influential in determining volunteer commitment. Phillips et al. (2019) noted the importance of social interactions between participants and program staff as seminal to continued engagement, a finding echoed in COASST seasoned participants' desire to interact with scientists and resource managers (Fig. 5, dark gray). On the other hand, Ganzevoort et al. (2017) found that individuals engaged in biodiversity monitoring overwhelmingly worked alone (90\% of their 2193 survey respondents). Loners are also present in COASST, as $\sim 9 \%$ of participants conduct their surveys alone (Parrish et al. 2019). Whether this reflective, loner-helper mentality is more attached to environmental hobbyists who develop a lifelong passion for a place or taxon (e.g., Wright et al. 2015, Jones et al. 2018) is an open question. In sum, divergent findings as to the degree to which social interactions play a role in determining participant motivation suggest that environmental citizen science is not a monolithic enterprise, but rather a collection of activity structures attracting and sustaining multiple possible identities and roles.

\section{CONCLUSIONS}

Environmental, hands-on programs allowing participants the chance to master skills and gain knowledge through repeated activity are one of the fastest expanding areas of citizen science (Parrish et al. 2019). Our study, together with other recent empirical and theoretical work, helps to set the stage for this expansion by collectively suggesting a set of four emergent principles that we believe are fundamental to successful recruitment and retention of participants, that is, successfully motivating people to become core members of the community of practice (Lave and Wenger 1991, Wenger 1998) that is both the citizen science and the science.

First, dominant motivations to participate appear to be situational or context oriented (Fig. 2), tied both to a strong sense of place (Haywood 2014, Haywood et al. 2016) and sense of biodiversity, including the subject of study (e.g., Jones et al. 2017) and outcomes for it (e.g., Carballo-Cárdenas and Tobi 2016). More generally, this suggests that hands-on citizen science with a focus on the environment can deepen the connection between people, place, and ecosystem via rigorous, bona fide science (National Academies of Sciences, Engineering, and Medicine 2018, Pagés et al. 2018).
Second, volunteers who remain engaged become committed to the activity and the organization (Vecina et al. 2012) and gradually adopt the primary essence and mode of the program as their own (Figs. 2-5). They increasingly adopt the mantle of science without becoming scientists. For environmental citizen science programs with a primary goal of generating rigorous science outcomes, participants strongly identify themselves as data collectors (Figs. 4 and 5) and may actively resist attempts to expand or change their role to incorporate additional science tasks (Frensley et al. 2017, Phillips et al. 2019). Allowing participants full "membership" in the science team with both respect and recognition according to their role (Phillips et al. 2019) will result in a committed and continuing data collection corps.

Third, both altruism and self-interest are powerful motivators that should be supported through initial and continued participation (Fig. 2). We suggest that the relative strength of each may be program dependent rather than related to the strength of engagement (sensu Rotman et al. 2012) and that both should be incorporated into program design.

Finally, participants clearly understand their role as having both scientific and social aspects (Figs. 4 and 5). They express both cognitive and affective engagement (Phillips et al. 2019) and also express that science is a social enterprise with positive emotional rewards (i.e., what Jaber and Hammer [2016] call epistemic affect). These findings suggest that citizen science programs that can effectively combine rigorous science with social interaction may be most successful in recruitment and retention. At the same time, attention to the types of environmental citizen science identities that collectively define engaged publics, from loner hobbyists (e.g., birders; Jones et al. 2017) to social data collectors (e.g., this study) to activism designers (Extreme Citizen Science; Stevens et al. 2014), will facilitate a future where every person has multiple opportunities to engage in authentic science research and learning while making a difference in the world.

Responses to this article can be read online at: http://www.ecologyandsociety.org/issues/responses. php/10956

\section{Acknowledgments:}

We thank the COASST beached bird participants who took part in the recruitment and retention surveys used herein and whose collective data have made the program what it is. Cindy Char, Jane Dolliver, and Erika Frost contributed to survey design, survey delivery and data collation. Hillary Burgess, Jackie Lindsey, Tina Phillips, Jennifer Preece, Andrea Wiggins, and two anonymous reviewers improved the work with critical reviews. J. K. Parrish acknowledges National Science Foundation DRL-1322820 and DRL-1114734 and Washington Sea Grant R/RCE-9 for supporting COASST.

\section{LITERATURE CITED}

Asah, S. T., and D. J. Blahna. 2013. Practical implications of understanding the influence of motivations on commitment to 
voluntary urban conservation stewardship. Conservation Biology 27(4):866-875. https://doi.org/10.1111/cobi.12058

Ballard, H. L., C. G. H. Dixon, and E. M. Harris. 2017. Youthfocused citizen science: examining the role of environmental science learning and agency for conservation. Biological Conservation 208:65-75. https://doi.org/10.1016/j.biocon.2016.05.024

Ballard, H. L., M. E. Fernandez-Gimenez, and V. E. Sturtevant. 2008. Integration of local ecological knowledge and conventional science: a study of seven community-based forestry organizations in the USA. Ecology and Society 13(2):37. https://doi.org/10.5751/ ES-02594-130237

Bruyere, B., and S. Rappe. 2007. Identifying the motivations of environmental volunteers. Journal of Environmental Planning and Management 50(4):503-516. https://doi.org/10.1080/09640560701402034

Buckland, S. T., A. E. Magurran, R. E. Green, and R. M. Fewster. 2005. Monitoring change in biodiversity through composite indices. Philosophical Transactions of the Royal Society B: Biological Sciences 360(1454):243-254. https://doi.org/10.1098/ rstb.2004.1589

Burgess, H. K., L. B. DeBey, H. E. Froehlich, N. Schmidt, E. J. Theobald, A. K. Ettinger, J. HilleRisLambers, J. Tweksbury, and J. K. Parrish. 2017. The science of citizen science: exploring barriers to use as a primary research tool. Biological Conservation 208:113-120. https://doi.org/10.1016/j.biocon.2016.05.014

Busser, J. A., and M. S. Norwalk. 2001. A case study of the willingness to volunteer for a public leisure service organization. LARNet: The Cyber Journal of Applied Leisure and Recreation Research 1:1-8.

Caissie, L. T., and E. A. Halpenny. 2003. Volunteering for nature: motivations for participating in a biodiversity conservation volunteer program. World Leisure Journal 45(2):38-50. https:// doi.org/10.1080/04419057.2003.9674315

Carballo-Cárdenas, E. C., and H. Tobi. 2016. Citizen science regarding invasive lionfish in Dutch Caribbean MPAs: drivers and barriers to participation. Ocean and Coastal Management 133:114-127. https://doi.org/10.1016/j.ocecoaman.2016.09.014

Clary, E. G., and M. Snyder. 1999. The motivations to volunteer: theoretical and practical considerations. Current Directions in Psychological Sciences 8(5):156-159. https://doi.org/10.1111/146$\underline{7-8721.00037}$

Cooper, C. B., J. Dickinson, T. Phillips, and R. Bonney. 2007. Citizen science as a tool for conservation in residential ecosystems. Ecology and Society 12(2):11. https://doi.org/10.5751/ES-02197-120211

Deci, E. L., and R. M. Ryan. 1986. The dynamics of selfdetermination in personality and development. Pages 171-194 in R. Schwarzer, editor. Self-related cognitions in anxiety and motivation. Erlbaum, Hillsdale, New Jersey, USA.

Dickinson, J. L., B. Zuckerberg, and D. N. Bonter. 2010. Citizen science as an ecological research tool: challenges and benefits. Annual Review of Ecology, Evolution, and Systematics 41:149-172. https://doi.org/10.1146/annurev-ecolsys-102209-144636

Domroese, M. C., and E. A. Johnson. 2017. Why watch bees? Motivations of citizen science volunteers in the Great Pollinator
Project. Biological Conservation 208:40-47. https://doi.org/10.1016/ j.biocon.2016.08.020

Engeström, Y. 2000. Activity theory as a framework for analyzing and redesigning work. Ergonomics 43(7):960-974. https://doi. org/10.1080/001401300409143

Engeström, R. 2009. Who is acting in an activity system? Pages 257-273 in A. Sannino, H. Daniels, and D. B. Gutierrez, editors. Learning and expanding with activity theory. Cambridge University Press, New York, New York, USA. https://doi. org/10.1017/CBO9780511809989.017

Falk, J. H., M. Storksdieck, and L. D. Dierking. 2007. Investigating public science interest and understanding: evidence for the importance of free-choice learning. Public Understanding of Science 16(4):455-469. https://doi.org/10.1177/0963662506064240

Frensley, T., A. Crall, M. Stern, R. Jordan, S. Gray, M. Prysby, G. Newman, C. Hmelo-Silver, D. Mellor, and J. Huang. 2017. Bridging the benefits of online and community supported citizen science: a case study on motivation and retention with conservation-oriented volunteers. Citizen Science: Theory and Practice 2(1):4. https://doi.org/10.5334/cstp.84

Ganzevoort, W., R. J. G. van den Born, W. Halffman, and S. Turnhout. 2017. Sharing biodiversity data: citizen scientists' concerns and motivations. Biodiversity Conservation 26 (12):2821-2837. https://doi.org/10.1007/s10531-017-1391-z

Halpenny, E. A., and L. T. Caissie. 2003. Volunteering on nature conservation projects: volunteer experience, attitudes and values. Tourism Recreation Research 28(3):25-33. https://doi. org/10.1080/02508281.2003.11081414

Haywood, B. 2014. A COASSTal sense of place: birds, beaches, and relationships between people and place in the Coastal Observation and Seabird Survey Team. Dissertation. University of South Carolina, Columbia, South Carolina, USA.

Haywood, B. K., J. K. Parrish, and J. Dolliver. 2016. Place-based, data-rich citizen science as a precursor for conservation action. Conservation Biology 30(3):476-486. https://doi.org/10.1111/ cobi.12702

Hidi, S., and K. A. Renninger. 2006. The four-phase model of interest development. Educational Psychologist 41(2):111-127. https://doi.org/10.1207/s15326985ep4102 4

Jaber, L. Z., and D. Hammer. 2016. Learning to feel like a scientist. Science Education 100(2):189-220. https://doi.org/10.1002/ sce. 21202

Jones, M. G., G. Childers, T. Andre, E. N. Corin, and R. Hite. 2018. Citizen scientists and non-citizen scientist hobbyists: motivation, benefits, and influences. International Journal of Science Education, Part B: Communication and Public Engagement 8(4):287-306. https://doi.org/10.1080/21548455.2018.1475780

Jones, M. J., E. N. Corin, T. Anre, G. M. Childers, and V. Stevens. 2017. Factors contributing to lifelong science learning: amateur astronomers and birders. Journal of Research in Science Teaching 54(3):412-433. https://doi.org/10.1002/tea.21371

Katz, D. 1960. The functional approach to the study of attitudes. Public Opinion Quarterly 24:163-204. https://doi.org/10.1086/266945 
Krapp, A. 1993. The construct of interest: characteristics of individual interests and interest-related actions from the perspective of a person-object-theory. Studies in Educational Psychology 4:1-20.

Krapp, A. 1999. Interest, motivation and learning: an educational-psychological perspective. European Journal of Psychology of Education 14(1):23-40. https://doi.org/10.1007/ $\underline{B F 03173109}$

Krapp, A. 2002. An educational-psychological theory of interest and its relation to SDT. Pages 405-426 in E. Deci and R. Ryan, editors. Handbook of self-determination research. University of Rochester Press, Rochester, New York, USA.

Krapp, A. 2005. Basic needs and the development of interest and intrinsic motivational orientations. Learning and Instruction 15 (5):381-395. https://doi.org/10.1016/j.learninstruc.2005.07.007

Krapp, A., S. Hidi, and K. A. Renninger. 1992. Interest, learning, and development. Pages 3-25 in K. A. Renninger, S. Hidi, and A. Krapp, editors. The role of interest in learning and development. Erlbaum, Hillsdale, New Jersey, USA.

Land-Zandstra, A. M., J. L. A. Devilee, F. Snik, F. Buurmeijer, and J. M. vanden Broek. 2016. Citizen science on a smartphone: participants' motivations and learning. Public Understanding of Science 25(1):45-60. https://doi.org/10.1177/0963662515602406

Lave, J., and E. Wenger. 1991. Situated learning: legitimate peripheral participation. Cambridge University Press, Cambridge, UK. https://doi.org/10.1017/CBO9780511815355

McKinley, D. C., A. J. Miller-Rushing, H. L. Ballard, R. Bonney, H. Brown, S. C. Cook-Patton, D. M. Evans, R. A. French, J. K. Parrish, T. B. Phillips, S. F. Ryan, L. A. Shanley, J. L. Shirk, K. F. Stepenuck, J. F. Weltzin, A. Wiggins, O. D. Boyle, R. D. Briggs, and M. A. Soukup. 2017. Citizen science can improve conservation science, natural resource management, and environmental protection. Biological Conservation 208:15-28. https://doi.org/10.1016/j.biocon.2016.05.015

Miles, I., W. C. Sullivan, and F. E. Kuo. 2000. Psychological benefits for volunteering for restoration projects. Ecological Restoration 18(4):218-227. https://doi.org/10.3368/er.18.4.218

Miller-Rushing, A., R. Primack, and R. Bonney. 2012. The history of public participation in ecological research. Frontiers in Ecology and the Environment 10(6):285-290. https://doi. org/10.1890/110278

National Academies of Sciences, Engineering, and Medicine. 2018. Learning through citizen science: enhancing opportunities by design. National Academies Press, Washington, D.C., USA. https://doi.org/10.17226/25183

National Research Council. 2009. Learning science in informal environments: people, places, and pursuits. National Academies Press, Washington, D.C., USA.

Nov, O., O. Arazy, and D. Anderson. 2014. Scientists@Home: what drives the quantity and quality of online citizen science participation? PLOS ONE 9(4):e90375. https://doi.org/10.1371/ journal.pone.0090375
Pagès, M., A. Fischer, and R. van der Wal. 2018. The dynamics of volunteer motivations for engaging in the management of invasive plants: insights from a mixed-methods study of Scottish seabird islands. Journal of Environmental Planning and Management 61(5-6):904-923. https://doi.org/10.1080/09640568.2017 .1329139

Parrish, J. K., T. Jones, H. K. Burgess, Y. He, L. Fortson, and D. Cavalier. 2019. Hoping for optimality or designing for inclusion: persistence, learning, and the social network of citizen science. Proceedings of the National Academy of Sciences of the United States of America 116(6):1894-1901. https://doi.org/10.1073/ pnas. 1807186115

Parrish, J. K., K. Litle, J. Dolliver, T. Hass, H. K. Burgess, E. Frost, C. W. Wright, and T. Jones. 2017. Defining the baseline and tracking change in seabird populations: the Coastal Observation and Seabird Survey Team (COASST). Pages 19-38 in J. A. Cigliano and H. L. Ballard, editors. Citizen science for coastal and marine conservation. Routledge, London, UK. https://doi. org/10.4324/9781315638966-2

Penuel, W. R., and J. V. Wertsch. 1995. Vygotsky and identity formation: a sociocultural approach. Educational Psychologist 30 (2):83-92. https://doi.org/10.1207/s15326985ep3002 5

Phillips, T. B., H. L. Ballard, B. V. Lewenstein, and R. Bonney. 2019. Engagement in science through citizen science: moving beyond data collection. Science Education 103(3):665-690. https:// doi.org/10.1002/sce.21501

Roth, W.-M., Y.-J. Lee, and P.-L. Hsu. 2009. A tool for changing the world: possibilities of cultural-historical activity theory to reinvigorate science education. Studies in Science Education 45 (2):131-167. https://doi.org/10.1080/03057260903142269

Rotman, D., J. Preece, J. Hammock, K. Procita, D. Hansen, C. Parr, D. Lewis, and D. Jacobs. 2012. Dynamic changes in motivation in collaborative citizen-science projects. Pages 217-226 in Proceedings of the ACM 2012 conference on computer supported cooperative work (Seattle, Washington, 11-15 February 2012). Association for Computing Machinery, New York, New York, USA. https://doi.org/10.1145/2145204.2145238

Ryan, R. L., R. Kaplan, and R. E. Grese. 2001. Predicting volunteer commitment in environmental stewardship programmes. Journal of Environmental Planning and Management 44 (5):629-648. https://doi.org/10.1080/09640560120079948

Schiefele, H., A. Krapp, M. Prenzel, A. Heiland, and H. Kasten. 1983. Principles of an educational theory of interest. Pages 1-35 in Seventh Biennial Meeting of the International Society for the Study of Behavioural Development (Munich, West Germany, 31 July-4 August 1983). [online] URL: https://www.researchgate.net/ publication/262535690

Stepenuck, K. F., and L. Green. 2015. Individual- and community-level impacts of volunteer environmental monitoring: a synthesis of peer-reviewed literature. Ecology and Society 20 (3):19. https://doi.org/10.5751/ES-07329-200319

Stetsenko, A. 2005. Activity as object-related: resolving the dichotomy of individual and collective planes of activity. Mind, 
Culture, and Activity 12(1):70-88. https://doi.org/10.1207/ s15327884mca1201_6

Stetsenko, A., and I. M. Arievitch. 2004. The self in culturalhistorical activity theory: reclaiming the unity of social and individual dimensions of human development. Theory and Psychology 14(4):475-503. https://doi.org/10.1177/0959354304044921

Stevens, M., M. Vitos, J. Altenbuchner, G. Conquest, J. Lewis, and M. Haklay. 2014. Taking participatory citizen science to extremes. IEEE Pervasive Computing 13(2):20-29. https://doi. org/10.1109/MPRV.2014.37

Theobald, E. J., A. K. Ettinger, H. K. Burgess, L. B. DeBey, N. R. Schmidt, H. E. Froehlich, C. Wagner, J. HilleRisLambers, J. Tewksbury, M. A. Harsch, and J. K. Parrish. 2015. Global change and local solutions: tapping the unrealized potential of citizen science for biodiversity research. Biological Conservation 181:236-244. https://doi.org/10.1016/j.biocon.2014.10.021

Vecina, M. L., F. Chacón, M. Sueiro, and A. Barrón. 2012. Volunteer engagement: does engagement predict the degree of satisfaction among new volunteers and the commitment of those who have been active longer? Applied Psychology 61(1):130-148. https://doi.org/10.1111/j.1464-0597.2011.00460.x

Vryan, K. D. 2007. Identity: social psychological aspects. Pages 2216-2220 in G. Ritzer, editor. The Blackwell encyclopedia of sociology. Blackwell, Malden, Massachusetts, USA. https://doi. org/10.1002/9781405165518.wbeosi006

Wenger, E. 1998. Communities of practice: learning, meaning, and identity. Cambridge University Press, Cambridge, UK. https:// doi.org/10.1017/CBO9780511803932

West, S., and R. Pateman. 2016. Recruiting and retaining participants in citizen science: what can be learned from the volunteering literature? Citizen Science: Theory and Practice 1 (2):15. https://doi.org/10.5334/cstp.8

Weston, M., M. Fendley, R. Jewell, M. Satchell, and C. Tzaros. 2003. Volunteers in bird conservation: insights from the Australian Threatened Bird Network. Ecological Management and Restoration 4(3):205-211. https://doi.org/10.1046/

j.1442-8903.2003.00169.x

Wright, D. R., L. G. Underhill, M. Keene, and A. T. Knight. 2015. Understanding the motivations and satisfactions of volunteers to improve the effectiveness of citizen science programs. Society and Natural Resources 28:1013-1029. https://doi.org/10.1080/089419$\underline{20.2015 .1054976}$ 
Appendix 1. Survey questions.

Participant surveys contained a series of binomial (e.g. Yes/No), multiple choice, Likert scale and free-write questions. For this analysis, we used two sets of questions (see below): (1) a freewrite question asking about reasons for joining/staying, and (2) a multi-category binomial question regarding roles and tasks.

\section{Free-write Questions:}

Please tell us briefly (1-2 sentences is fine) why you chose to be involved with this program. (new participants, 2012)

Please tell us briefly (1-2 sentences is fine) why you continue to be involved with this program. (seasoned participants, 2012)

People sign up to participate in citizen science programs for many different reasons. Why did you join COASST? (new participants, 2016)

People participate in citizen science programs for many different reasons. Why do you continue to survey for COASST? (seasoned participants, 2016)

\section{Roles \& Tasks Questions (new and seasoned participants, 2016):}

New Participants: "Science is a process involving many different tasks. We would like you to think about two groups of people in science:

- yourself, and by extension all participants in citizen science programs (like COASST)

- citizen science program staff

We realize that you may not yet be totally familiar with the COASST program, but you may be familiar with science, and with other citizen science programs. Let this experience guide your answers. Please look over the task list below and check any task you think participants in a citizen science program would do on a regular basis. Then think about program staff- what tasks do you think they perform? You may double assign any task, and you do not need to assign all tasks."

Seasoned Participants: "Science is a process involving many different tasks. We would like you to think about three groups of people in science:

- yourself, as a COASST participant

- COASST Staff, including the Executive Director

- Scientists outside of the COASST program

Please look over the task list below and check any task you currently perform, and any task you would like to begin performing. Then think about COASST staff, and separately about scientists associated with COASST. What tasks do you think each of these groups perform? You may assign any task to more than one group, and you do not need to assign all tasks."

Task list (for both versions): Recruiting others to join the program; Collecting data; Performing statistical analyses; Making precise measurements; Entering data into a database; Graphing program data; Telling others about the data, or the program; Giving presentations about program data; Writing about program data; Verifying that the data are accurate; Creating data collection protocols; Developing trainings for participants; Developing data collection materials; Training 
new participants; Obtaining funding for the program; Working directly with scientists; Working directly with resource managers. 
Appendix 2. Codebook.

Within interests, seven action and 11 object codes were iteratively identified and defined. The object code COASST was broken down into three exclusive child codes. Within sense of self, 17 codes were identified. Two additional codes were identified: self-esteem and importance (see Miscellaneous below). Codes are sorted into four categories: interest-action, interest-object, sense-of-self, and miscellaneous. Within each category, codes are sorted in rough order of frequency across the two respondent populations (see Figures 2, 4). Bulleted lists describe contrary states (i.e., what the code is not).

Actions: Defined by the verb form or other indication of action or doing; almost always in association with one or more objects of interest, i.e., how the participant wishes to or describes interacting with an object of interest as a functional motivation to join or remain active in COASST.

1. Being Outdoors: Participants say they like/love/appreciate being outdoors, outside and/or in nature. This code includes aesthetics - the beautiful place. This code should also be applied whenever participants talk about walking the beach.

- The difference between this code and "sense of place" is that this code does not have to be linked to a specific location or express an emotional attachment.

- The difference between this code and physical/mental health is that this code does not have to name a specific benefit (like health) of being outside.

2. Help/Volunteer/Contribute: Participants explicitly mention that they contribute to, volunteer for, and/or help with something. They might mention their previous volunteer experience which becomes a reason for them to join COASST.

- If they only talk about doing something (e.g. " I want to make even a small difference in our understanding of the changes taking place in our coastal ecology."), that is not enough.

- Pay attention to what is being "helped/contributed/supported" - if the helping equates to conserving or protecting (e.g., "help bird-life" or "help environment") then code as Conserve/Protect not Help/Volunteer/Contribute.

- If they write about helping an organization that engages in conservation, and also write about conserving/protecting actions they want to engage in, then code as both Conserve/Protect and Help/Volunteer/Contribute.

- Be aware that contribute can have multiple meanings.

- I want to contribute to science. - code as Help

- I want to contribute to the greater good (e.g., to help the earth (P4177)) - code as Greater Good

3. Learn/Understand/Experience/Awareness: Participants want to increase, improve on or gain understanding, knowledge, skills or experience (or have already gained through participation). They express curiosity about something (but not including the program in general); want to learn about something; want to deepen, sharpen or increase their awareness of or realization about something; or encounter challenges and puzzles, all through participating in COASST. There 
must be a stated sense of gain. Participants might explicitly mention the specific kind of knowledge or skills they want to get/improve on. This is about the participant learning, not about facilitating the learning of others.

- If participants only use a single word "curiosity" without saying what they are curious about, use this code.

- If the reference refers to honing skills or keeping up skills or otherwise not eroding their skill base, use Skill/Task.

- Discovering or finding something new or different, without any other information about learning, doesn't count.

4. Conserve/Protect/Manage: Participants say they want to protect/preserve something (by assumption, from harm or destruction). Participant desires to contribute to work that helps protect and preserve natural resources; or manage resources.

- Assessing the environment, or environmental health - do not code for conserve.

- Contributing to or maintaining the health of the environment - do code for conserve.

5. Monitor/Observe: Participants say they want to monitor and observe beaches and/or wildlife and/or processes. Participants mention change over time. This includes mention of creating or maintaining a baseline.

- This code should only be used when the participant refers to COASST data locally. That is, trends on their beach not "global COASST" trends.

- This is not the same as data collection, unless the reference also includes specifics of monitoring, observation, and/or baseline.

If a participant refers to himself/herself as a "monitor" this code may not be appropriate. Decide from context whether the more appropriate code is "steward."

6. Enjoyment: Participants find participating in COASST fun or enjoyable.

7. Maintaining Personal Health: Participants want to stay in good physical or mental health by engaging in COASST surveys, including physical benefits of walking on beach, or hiking; and mental benefits of "brain exercise" associated with COASST and citizen science participation more broadly.

Objects: The noun form of an interest, function or reason for joining or staying active in COASST; may connect to one or more actions of interest.

1. Birds: Participants say they are interested in birds/birding or learning more about birds, want to help (conserve/protect/study) birds, or believe the importance of collecting bird data.

- When using the code "birder" this code must also be used; however, when using this code, the code "birder" is not necessarily invoked unless the participant explicitly mentions that they are a birder/bird watcher. 
2. Beach: Participants refer directly to the/their beach, or to the coastal or marine environment.

- If there is mention of "environment" and no mention of marine or coastal or coast or beach, code as "environment."

- This code has one child code:

Sense of place: Participants describe their connection to a specific place (e.g., a named beach, use of words like "local"); and/or use possessives regarding place (e.g., "my" beach). The attachment can be emotional. There will be a nearly complete overlap between Sense of Place and Beach, although the latter code will be larger.

3. Environment/Nature: Participants talk about the environment or about nature as a place (e.g., out in nature).

- This is not the same as environmentalism, or environmentalist (see Steward).

- If the quote refers to watching or observing nature, then code as "Wildlife." (e.g., I love watching nature.)

4. COASST: Participants make explicit mention of the COASST program.

- Do not use this code if the reference refers to COASST only as a reflection of the question, e.g. Q: "Why do you continue to participate in COASST?" A: "I want to be part of COASST because...."

- Participants should explicitly provide their evaluation of the program or practice (e.g., the program/practice is interesting, I like/enjoy/love the program/practice).

- This code has three child codes:

COASST Program: Participants talk about why they are motivated by/attracted to the COASST program. References can refer to COASST as a whole (e.g., an easy commitment (P3107), successful project), or a part of COASST (e.g., materials, staff).

- Notes on grammar and completeness of answers:

- "The COASST program is interesting." Code as COASST Program.

○ "It's interesting" "Sounds interesting." Code as COASST Program.

- "Interest." Too vague, do not code as COASST Program.

- COASST data/database/mission. Code as COASST Program/Data/Results. Practice of COASST: Participants refer to their particular experience of doing COASST the practice or process of COASST surveys.

- The difference between this code and Skill/Task is that Practice refers to the totality of their activity or work for COASST, and/or when they speak about the process or procedure of COASST; Skill/Task refers to a particular action: measuring the wing, handling the birds.

- I like identifying birds. Code as Skill/Task.

- The process of bird identification is interesting. Code as Practice.

- Field work. Code as Practice.

COASST Program Data/Results: Participants explicitly refer to the value or use of COASST data or results. 
- This code should be used when the participant refers to COASST data globally, that is, not only trends on their beach but "global COASST" trends or "COASST data stories."

- If the reference also refers to the participant collecting data, also code as "Data Collector"

- If the reference only refers to the participant collecting data, only code as "Data Collector"

- If the reference only refers to the data/results without mentioning collection, only code as "Data/Results"

5. Science: Specific references to science. Participants may espouse: (1) Interest in and/or desire to be involved in science, or in a scientific study. (e.g., " Being outdoors + Science"); (2) A specific science subject or discipline (e.g., ecology, marine biology); (3) Contributing to or increasing knowledge, furthering knowledge, knowledge as the general subject.

- Do not use this code for increasing participants' personal knowledge, which should be coded Learn.

- References to citizen science are not included in this code.

- References to particular skills or tasks that are (or could be) part of science (e.g., data collection, baseline data or monitoring) are not included in this code.

6. Citizen Science: Participants mention citizen science in general, and/or explicit mention of projects/programs other than COASST. This code does NOT include direct reference to self, as in "I am a citizen scientist." "I volunteer for..."

7. Wildlife: Similar to "Birds," but referring to all other organisms besides birds, or larger taxonomic or ecological categories (e.g., "wildlife"). If wildlife is not explicitly mentioned, and some more general description (e.g., cool stuff on the beach) is provided, use this code. But if the general description is too vague (e.g., am concerned about the condition of the beach and what washes ashore), don't use this code.

- If reference refers to interest in nature as an overall thing (towards environment or ecosystem) code as "Environment/Nature."

- If reference refers to some action associated with nature, like watching or observing or monitoring, code as "'Wildlife."

8. Skill/Task: Participants mention or describe a particular skill or task they want to learn, (would) like to perform, or feel that performing is important or worthwhile.

- General phrasing (e.g., contribute to science, gather data, help monitor, survey the beach) is not included in this code. (See "Science" "Monitor/Observe").

9. Greater Good: Participants refer to a larger positive outcome of their participation and/or the work or the program beyond a personal benefit.

- Making a contribution, or making a positive contribution, without some larger subject (e.g., world, earth, society, environment or science) - do not include. 
10. Worldview: Participants talk about their beliefs and value system - their socio-ethical norms used to guide behavior and decisions. If participants mention sharing/supporting COASST mission/aims/goals, use this code.

- This code does not include the word believe (the verb form; e.g., I believe citizen science is worthwhile), but only the noun form (belief; e.g., It reflects our beliefs).

- This code does not include the word value as a verb (e.g., I value it), only as a noun (e.g., I hold this as a value).

- This code can be combined with greater good.

11. Marine Debris: All references to picking up debris or trash (e.g., plastic).

Sense of Self: Participants say who they were/are. There is a sense of permanence, of time and of intent. Simple mentions of an action or interest without a long-term sense of time is not enough. A participant can have many senses of self (i.e., roles) which are themselves wrapped up into larger identities, of which there can also be multiple.

Explicit statements - the participant is overt about an identity, using words like "I am" "I was" "As a [...], I..."

Implicit statements - the participant describes activity that is commonly associated with a particular set of tasks or roles. The activity can be a long-term, even lifetime long.

COASST-relevant statements - the participant is referring to activities/roles that are associated with and/or have come about because of participating in COASST.

1. Data Collector (explicit; could be COASST): All statements referring to data collecting. Participants must refer directly to the data they are collecting or gathering, or the surveys they are doing.

2. Science Team Member (implicit): All statements referring to helping, assisting, or contributing to science or research, without any specific reference to what the participant is/will be doing (e.g., "Data collector").

- Do not use this code if participants refer to their work for COASST or they are involved in/part of COASST (See "Survey Team Member" or "Collective").

3. Survey Team Member (COASST): Any mention of membership in the COASST survey team. Must refer to other COASST participants that the respondent surveys with, and/or COASSTers in the immediate vicinity that the respondent regularly associates with relative to their COASST work.

- This code does not include statements about all COASSTers, the power of many data collectors, or other statements that do not refer to specific individuals (See "Collective").

- If the participant only mentions helping family members/friends but does not provide the team as a context, do not include. 
But if participants mention "working with partner" (especially the partner is not their family members, but other COASSTers), it shows participants have a mindset about the larger group the survey team and they partner with others to work in the same team, use this code.

4. Collective (COASST): Participants refer to their part of a larger (collective) effort composed of many like individuals in the sense of everyone doing the same thing (collecting the same data, or collecting data the same way) and in the sense of the resultant information/data being important/useful because of its scale. In the collective, participants are aware of the entire group, but don't actually know many/any of the other participants personally. Thus, this is not membership in a socially-structured group. There must be an explicit sense that there is a larger effort beyond the individual. There can be a sense that the collective effort is more than the sum of the parts.

- This code is different from "Greater Good" in that it is focused on membership in a greater/larger group of people all doing the same thing as well as on what comes out of the collective work.

5. Citizen Scientist (explicit): Participants refer to themselves directly as a "citizen scientist;" participants refer to their volunteerism in named citizen science programs other than COASST, including in science-based or natural resource-management-based organizations (e.g., national parks, NOAA, national marine sanctuaries, state wildlife agencies, etc.).

6. Family: Any mention of a familial connection (including marriage). Pets don't count! If the entire quote contains "We" or "Us" with no "I" then a couple is implied. Code as Family.

7. Friend, Colleague: Any mention of specific people other than familial connections; includes friends, colleagues, neighbors and others.

This code does not include:

- "the collective" - code as Collective

- $\quad$ any reference to a specific survey team - code as "Survey Team Member"

- mention of a group of unspecified people (e.g., beachgoers, folks on the beach) - code as "Community"

8. Community: Any mention of a general social relationship with a specified or unspecified group (e.g., beachgoers, folks on the beach, my church, my community).

- This code does not include the "scientific community" or other communities of practice or interest that are not geographic and/or social.

9. Learner (explicit): Participants refer to themselves as engaged in long-term, or even life-long learning; or that they are actively, constantly or consistently engaged in learning; or that they have a strong interest/like/love of or passion for learning about many different types of things. There must be a sense beyond the immediate; one-time learning does not count. The references could also: (1) Refer to self in the role of student relative to others as teacher; (2) Convey the 
sense of another object of learning, a new object of learning, beyond what they already have learned about/know. This is the sense of additive, or implicit life-long learning.

10. Educator (explicit): Any mention of being/having been a professor, teacher, education specialist; includes both formal and informal settings.

11. Birder (explicit): Participants call themselves birders or birdwatchers.

12. Naturalist (explicit, implicit): Similar to "Birder" but with explicit reference to watching or observing nature beyond birds and/or directly to being a naturalist.

- If the word naturalist is not used, participants must use the noun form of observe (e.g., "observation," "make observations" "observer") combined with a sense of multiple or continuing - observations conducted over time.

- This code does not include the verb form of observe (e.g., "observing nature") unless the quote also contains more explicit information about observing over time and building a baseline of personal knowledge (multiple observations, mental model).

13. Steward (explicit): Participant states they are protectors, stewards or conservers of something. This code includes activism or action in service of the environment (e.g., environmentalist).

14. Other working world Identity: Any mention of non-science, non-education working world or career identities not otherwise captured in the coding scheme.

15. Retiree: When participants explicitly mention they are retired or are retirees.

16. Credentials - (STEM) Degree: Participants refer to their educational background, or any degrees or certifications.

17. Credentials - STEM Job: Participants mention their work, job titles/positions. When job titles/positions are not explicitly mentioned, participants must describe their work experience with sufficient detail as to allow inference of a present/past scientific job.

\section{Miscellaneous Codes:}

1. Importance: Participants mention what they think, feel, believe and/or what the program is, does or produces is important. At least one of the following keywords must be present: important, worth, valuable, meaningful.

2. Self-esteem: Participating in COASST makes participants feel that they are useful and needed, they feel better about themselves, feel good or are rewarded for/by their efforts, and/or are proud of their efforts. It could be a way to prove the value of self.

- Mention of only a good/better way of using time is not enough. 
Appendix 3. Tables.

Table A3.1. Results of Z-tests determining differences between new and seasoned participant motivations (object of interest, action of interest, sense of self) within year $(2012,2016)$ and within the pooled dataset. Codes where the pooled dataset comparison was not significant whereas either year-specific comparison was significant are bolded. Note that codes with less than $3 \%$ (object, action) or 1\% (senses of self) occurrence within all answering populations are included (i.e. the complete dataset).

\begin{tabular}{|c|c|c|c|c|c|c|}
\hline \multirow[t]{2}{*}{ Code } & \multicolumn{2}{|c|}{2012} & \multicolumn{2}{|c|}{2016} & \multicolumn{2}{|c|}{ Pooled } \\
\hline & Z & $\mathrm{P}$ & $\mathrm{Z}$ & $\mathrm{P}$ & Z & $P$ \\
\hline Beach & -1.50 & & -2.96 & 0.00 & -2.99 & 0.00 \\
\hline Birds & 2.11 & 0.04 & 2.53 & 0.01 & 3.33 & 0.00 \\
\hline COASST (parent code) & -3.27 & 0.00 & -1.22 & & -3.32 & 0.00 \\
\hline COASST.data/results & -3.49 & 0.00 & -2.38 & 0.02 & -4.10 & 0.00 \\
\hline COASST.practice & -0.50 & & -0.67 & & -0.85 & \\
\hline COASST.program & -1.24 & & 0.44 & & -0.73 & \\
\hline Citizen science & 1.32 & & 2.28 & 0.02 & 2.45 & 0.01 \\
\hline Environment/Nature & 2.59 & 0.01 & 1.22 & & 2.69 & 0.01 \\
\hline Marine debris & 0.28 & & -1.47 & & -0.34 & \\
\hline Science & -0.64 & & -1.33 & & -1.43 & \\
\hline Skill/Task & -0.58 & & -0.30 & & -0.64 & \\
\hline Wildlife & 1.83 & & 0.38 & & 1.53 & \\
\hline Greater good+worldview & -2.98 & 0.01 & 1.01 & & -1.35 & \\
\hline Being outdoors & -1.62 & & -2.39 & 0.02 & -2.95 & 0.00 \\
\hline Conserve/Protect & -0.40 & & -0.31 & & -0.40 & \\
\hline Enjoyment & -2.59 & 0.01 & -0.84 & & -2.54 & 0.01 \\
\hline Help/Contribute & -0.23 & & 1.87 & & 0.91 & \\
\hline Learn & 1.54 & & 3.05 & 0.00 & 2.99 & 0.00 \\
\hline Monitor/Observe & -3.49 & 0.00 & -1.85 & 0.06 & -3.87 & 0.00 \\
\hline Preserve health & -1.78 & 0.08 & -1.34 & & -2.25 & 0.02 \\
\hline Birder & 3.13 & 0.00 & 1.26 & & 3.31 & 0.00 \\
\hline Citizen scientist & 0.78 & & 2.11 & 0.04 & 1.91 & \\
\hline Collective & -2.29 & 0.02 & -0.70 & & -2.21 & 0.03 \\
\hline Data collector & -0.47 & & -0.11 & & -0.58 & \\
\hline Educator & -1.22 & & 0.65 & & -0.30 & \\
\hline Credentials-degree. & 2.06 & 0.04 & 1.26 & & 2.41 & 0.02 \\
\hline Credentials-job & 1.99 & 0.05 & 1.32 & & 2.17 & 0.03 \\
\hline Learner & 0.78 & & -0.80 & & 0.38 & \\
\hline Naturalist & 1.17 & & -0.73 & & 0.31 & \\
\hline Other identity & 1.57 & & 1.26 & & 1.93 & \\
\hline
\end{tabular}




$\begin{array}{rcccccc}\text { Retiree } & 1.73 & 0.08 & 2.07 & 0.04 & 2.57 & 0.01 \\ \text { Science team member } & -1.92 & & 0.21 & & -1.36 & \\ \text { Community } & 0.11 & & -0.80 & & -0.34 & \\ \text { Family } & -2.19 & 0.03 & -0.74 & & -2.18 & 0.03 \\ \text { Friend/Colleague } & 1.17 & & 2.37 & 0.02 & 2.38 & 0.02 \\ \text { Survey team member } & -1.28 & & -0.80 & & -1.55 & \\ \text { Steward } & 1.33 & & -0.73 & & 0.95 & \\ \text { Self-esteem } & -2.38 & 0.02 & -2.68 & 0.01 & -3.67 & 0.00 \\ \text { Importance } & -3.40 & 0.00 & -5.45 & 0.00 & -6.42 & 0.00\end{array}$

Table A3.2. Results of Chi-square contingency tables comparing new to seasoned participant counts for 17 tasks (see Figure 5). Non-significant comparisons (i.e., new and seasoned participant populations are coincident) are bolded.

\begin{tabular}{rcccc}
\hline \hline & \multicolumn{2}{c}{ Will do vs Do } & \multicolumn{2}{c}{ Will do vs (Do + Want to Do) } \\
Task title & $\begin{array}{c}\text { Chi-square } \\
\text { value }\end{array}$ & P value \\
\hline Collect data & $\mathbf{0 . 3 9}$ & $\mathbf{0 . 5 3}$ & $\mathbf{0 . 3 9}$ & $\mathbf{0 . 5 3}$ \\
Make measurements & $\mathbf{0 . 0 1}$ & $\mathbf{0 . 9 0}$ & $\mathbf{0 . 7 1}$ & $\mathbf{0 . 4 0}$ \\
Communicate results & 12.20 & 0.00 & 8.46 & 0.00 \\
Recruit others & 49.03 & 0.00 & 33.25 & 0.00 \\
Interact with scientists & 196.52 & 0.00 & 76.61 & 0.00 \\
Verify data/results & 20.76 & 0.00 & 15.68 & 0.00 \\
Interact with managers & 136.97 & 0.00 & 53.78 & 0.00 \\
Enter data & $\mathbf{0 . 2 0}$ & $\mathbf{0 . 6 6}$ & $\mathbf{1 . 4 2}$ & $\mathbf{0 . 2 3}$ \\
Create trainings & 37.39 & 0.00 & 11.65 & 0.00 \\
Do presentations & 98.36 & 0.00 & 15.40 & 0.00 \\
Create materials & 49.33 & 0.00 & 26.45 & 0.00 \\
Write about data & 41.23 & 0.00 & 13.64 & 0.00 \\
Recruit funds & 50.72 & 0.00 & 34.52 & 0.00 \\
Train others & 46.80 & 0.00 & 19.28 & 0.00 \\
Perform statistics & 24.20 & 0.00 & 4.92 & 0.03 \\
Graph data & 30.37 & 0.00 & $\mathbf{2 . 0 7}$ & $\mathbf{0 . 1 5}$ \\
Create protocols & 23.87 & 0.00 & 7.81 & 0.01 \\
\hline
\end{tabular}

